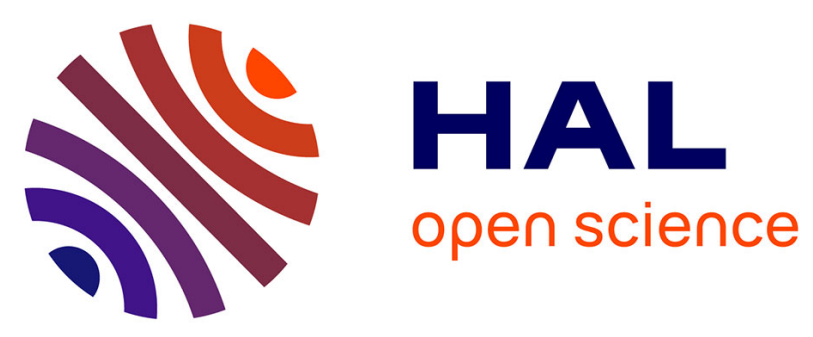

\title{
Spectral Editing in Solid-State MAS NMR Quadrupolar Nuclei using Selective Satellite Inversion
}

\author{
K.K. Dey, S. Prasad, J. Ash, M. Deschamps, P.J. Grandinetti
}

\section{To cite this version:}

K.K. Dey, S. Prasad, J. Ash, M. Deschamps, P.J. Grandinetti. Spectral Editing in Solid-State MAS NMR Quadrupolar Nuclei using Selective Satellite Inversion. Journal of Magnetic Resonance, 2007, 185, pp.237-241. 10.1016/j.jmr.2006.12.013 . hal-00122562

\section{HAL Id: hal-00122562 https://hal.science/hal-00122562}

Submitted on 3 Jan 2007

HAL is a multi-disciplinary open access archive for the deposit and dissemination of scientific research documents, whether they are published or not. The documents may come from teaching and research institutions in France or abroad, or from public or private research centers.
L'archive ouverte pluridisciplinaire $\mathbf{H A L}$, est destinée au dépôt et à la diffusion de documents scientifiques de niveau recherche, publiés ou non, émanant des établissements d'enseignement et de recherche français ou étrangers, des laboratoires publics ou privés. 


\title{
Spectral Editing in Solid-State MAS NMR of Quadrupolar Nuclei using Selective Satellite Inversion
}

\author{
Krishna K. Dey, ${ }^{a}$ S. Prasad, ${ }^{a}$ Jason Ash, ${ }^{a}$ \\ Michael Deschamps, ${ }^{\mathrm{b}}$ Philip J. Grandinetti ${ }^{\text {a, }}{ }^{2}$ \\ ${ }^{a}$ Department of Chemistry, The Ohio State University, $120 \mathrm{~W} .18^{\text {th }}$ Avenue, \\ Columbus, Ohio 43210-1173 \\ ${ }^{\mathrm{b}}$ CRMHT-CNRS, UPR4212, 45071 Orleans cedex2, France
}

\begin{abstract}
A sensitivity enhancement method based on selective adiabatic inversion of a satellite transition has been employed in a $(\pi / 2)_{\mathrm{CT}^{-}}-(\pi)_{\mathrm{ST}_{1}}-(\pi / 2) \mathrm{CT}$ spectral editing sequence to both enhance and resolve multisite NMR spectra of quadrupolar nuclei. In addition to a total enhancement of 2.5 times for spin $3 / 2$ nuclei, enhancements up to 2.0 times is reported for the edited sites in a mixture of rubidium salts.
\end{abstract}

Key words: Quadrupolar Nuclei, Sensitivity enhancement, Inversion, Spectral editing.

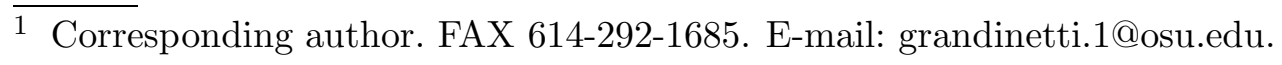


Rotor Assisted Population Transfer (RAPT) is a method[1,2] for enhancing the solid-state NMR central transition (CT) sensitivity of half-integer quadrupolar nuclei by transferring populations from the (unobserved) satellite transitions (ST) through selective saturation of the satellite transitions. An improved RAPT sequence using Frequency-Switched Gaussian pulses (FSG-RAPT) was later designed[3] to provide not only a more robust experimental enhancement but also the ability to measure quadrupolar coupling constants, $C_{q}$. This approach combines the sensitivity advantage of the central transition with the $C_{q}$ measurement precision advantage of the satellites. The dependence of the FSG-RAPT enhancement on offset frequency for nuclei with different $C_{q}$ values was also exploited to design the $(\pi / 2)_{\mathrm{CT}}-\mathrm{RAPT}-(\pi / 2)_{\mathrm{CT}}$ and $\mathrm{RAPT}-(\pi)_{\mathrm{CT}}-\mathrm{RAPT}-(\pi / 2)_{\mathrm{CT}} \quad$ schemes, for the selective excitation or suppression, respectively, of nuclei with large quadrupolar couplings[4]. These methods, specifically $(\pi / 2)_{\mathrm{CT}}-\mathrm{RAPT}-(\pi / 2)_{\mathrm{CT}}$, have been successfully utilized to understand the complex structure of Pyrex ${ }^{\circledR}$ by ${ }^{11} \mathrm{~B}$ NMR [5]. More recently, Smith and Seith [6] used $(\pi / 2)_{\mathrm{CT}}-\mathrm{RAPT}-(\pi / 2)_{\mathrm{CT}}$ to simplify a complex ${ }^{93} \mathrm{Nb}$ spectrum in a layered perovskite, and, additionally, appended the $(\pi / 2)_{\mathrm{CT}}$ - RAPT scheme to QPASS [7] to edit ${ }^{93} \mathrm{Nb} \mathrm{NMR}$ spectrum of $\mathrm{KCa}_{2} \mathrm{Nb}_{3} \mathrm{O}_{10}$ that contains two overlapping niobium sites. Also, the RAPT editing schemes have been applied to selective ${ }^{23} \mathrm{Na}-{ }^{1} \mathrm{H}$ cross polarization experiments, and to simplfy heteronuclear correlation spectra in various Na salts [8].

Recently, Wasylishen and coworkers[9] demonstrated that a hyperbolic secant pulse[10] can provide even greater central transition enhancements through a selective inversion of the satellite transitions[11]. Many theoretical details behind this approach have yet to be worked out, but the successful use of a hyperbolic secant pulse to invert the full manifold of satellite spinning sidebands represents an exciting possibility for central transition sensitivity enhancements, selective excitation or suppression of sites, and $C_{q}$ measurements, as was the case for RAPT.

In this communication, we report a new scheme for spectral editing based on the selective inversion obtained using the WURST pulse shape for adiabatic inversion[12,13]. WURST stands for Wideband, Uniform rate, Smooth Truncation: WURST operates at a lower peak radiofrequency field level than a hyperbolic secant pulse[10], prevents out-of-band excitation and inverts uniformly on a wide frequency range. The amplitude, phase and the excitation profile for the shaped pulse are shown in Fig. 1. We show that (1) a single WURST inversion pulse applied to single satellite transition spinning sideband can invert the full manifold of satellite spinning sidebands, and (2) selective inversion of resolved satellite spinning sidebands can be used to perform spectral editing of overlapping sites in a central transition spectrum. At the same time, substantial sensitivity enhancements of up to 2.0 times for the edited sites are reported.

In Fig. 2A is the CT resonance and part of the ST spinning sideband resonances for the three crystallographically distinct ${ }^{87} \mathrm{Rb}$ sites in $\mathrm{RbNO}_{3}$. With similar quadrupolar coupling constants[15], all three sites are overlapping in the $\mathrm{CT}$ and $\mathrm{ST}$ resonances. As shown in Fig. 2B, by applying a WURST inversion pulse on a single ST spinning sideband, which contains all three sites, an enhancement of all three sites in the central transition spectrum is obtained. The en- 

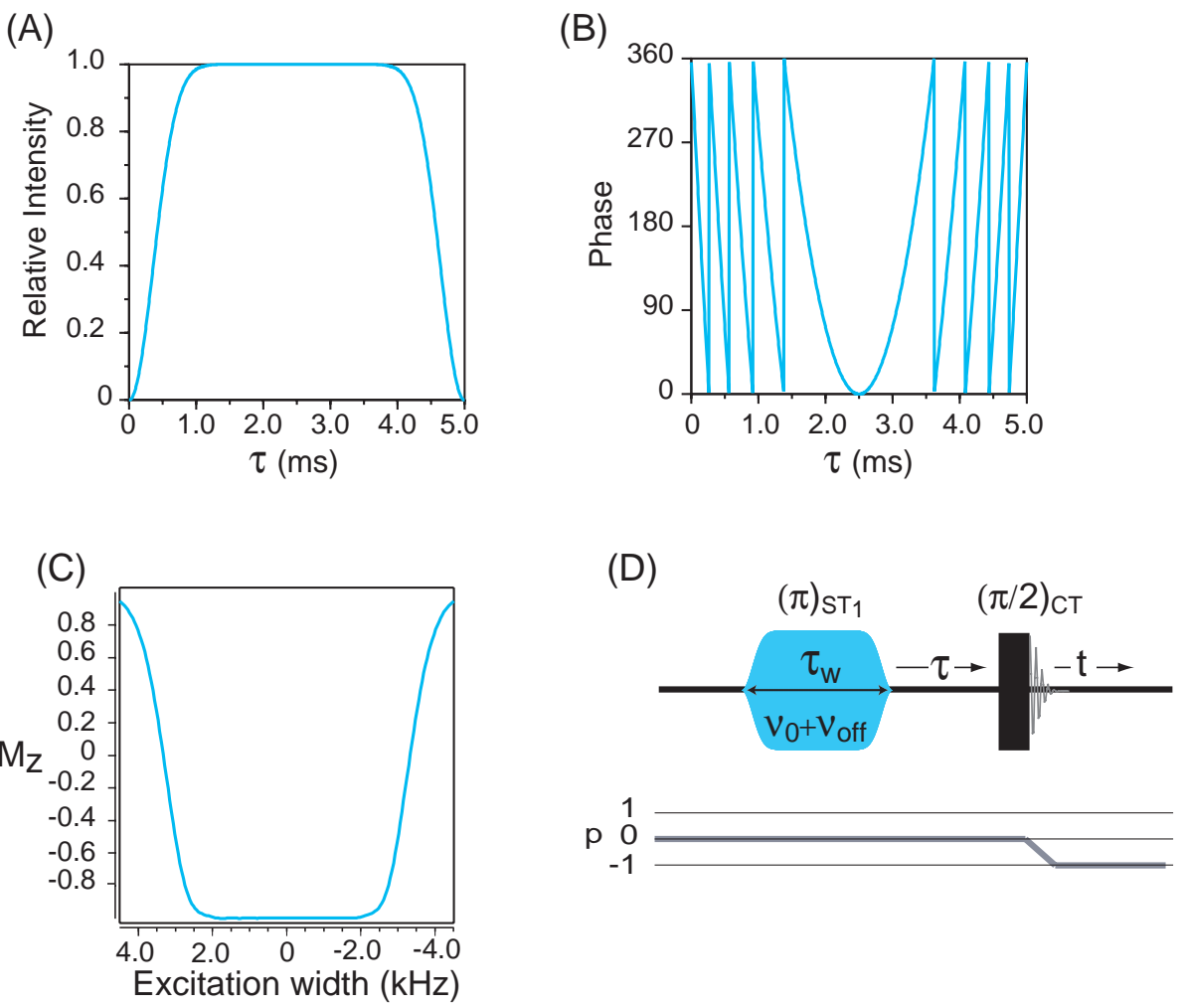

Fig. 1. (A) Amplitude and (B) phase as a function of the pulse length of the WURST pulse. (C) magnetization profile as a function of frequency offset. The pulse length and the excitation width are as shown. (D) The $(\pi)_{\mathrm{ST}_{1}}-(\pi / 2)_{\mathrm{CT}}$ sequence, where the selective $\pi$ rotation of the innermost satellite is accomplished by adiabatic inversion using the WURST pulse.

hanced spectrum was obtained by applying a $5 \mathrm{~ms}$ inversion pulse on the $n=6 \mathrm{ST}$ spinning sideband, located at an offset of $122.3 \mathrm{kHz}$ from the CT. An enhancement of 2.5 times is observed, and equally as important, the enhancement is uniform though out the line shape. The enhancement factor was identical when applied to individual spinning sidebands ranging from $n=5$ to 17 (offset range $100-300 \mathrm{kHz}$ ). Again, we emphasize that the adiabatic WURST inversion pulse was applied to a single spinning sideband. This method differs from that of Siegel et al.[9,16] who applied double frequency adiabatic inversion pulses at frequencies far off resonance with single site systems such as ${ }^{87} \mathrm{RbClO}_{4},{ }^{27} \mathrm{Al}(\text { acac })_{3}$ and ${ }^{55} \mathrm{Mn}_{2}(\mathrm{CO}){ }_{10}[9,16]$.
The $(\pi / 2)_{\mathrm{CT}}-$ RAPT $-(\pi / 2)_{\mathrm{CT}}$ approach $[3,4]$ for selective excitation of resonances with the largest $C_{q}$ values also exists with adiabatic inversion pulses. However, there is an additional possibility with adiabatic inversion pulses, not available with RAPT, for selective excitation amongst sites with similar $C_{q}$ values, provided the satellite transitions resonances of different sites are resolved. In fact, this possibility is enhanced for higher spin nuclei where the secondorder anisotropic width of the innermost satellite is narrower than the central transition under MAS (assuming the rotor angle is accurately set). To illustrate this aspect, simulated spectra of central and satellite transitions as a function of nuclear spin $I$ are shown in Fig. 3. The spectra were simulated with a spinning frequency of $10 \mathrm{kHz}$ 


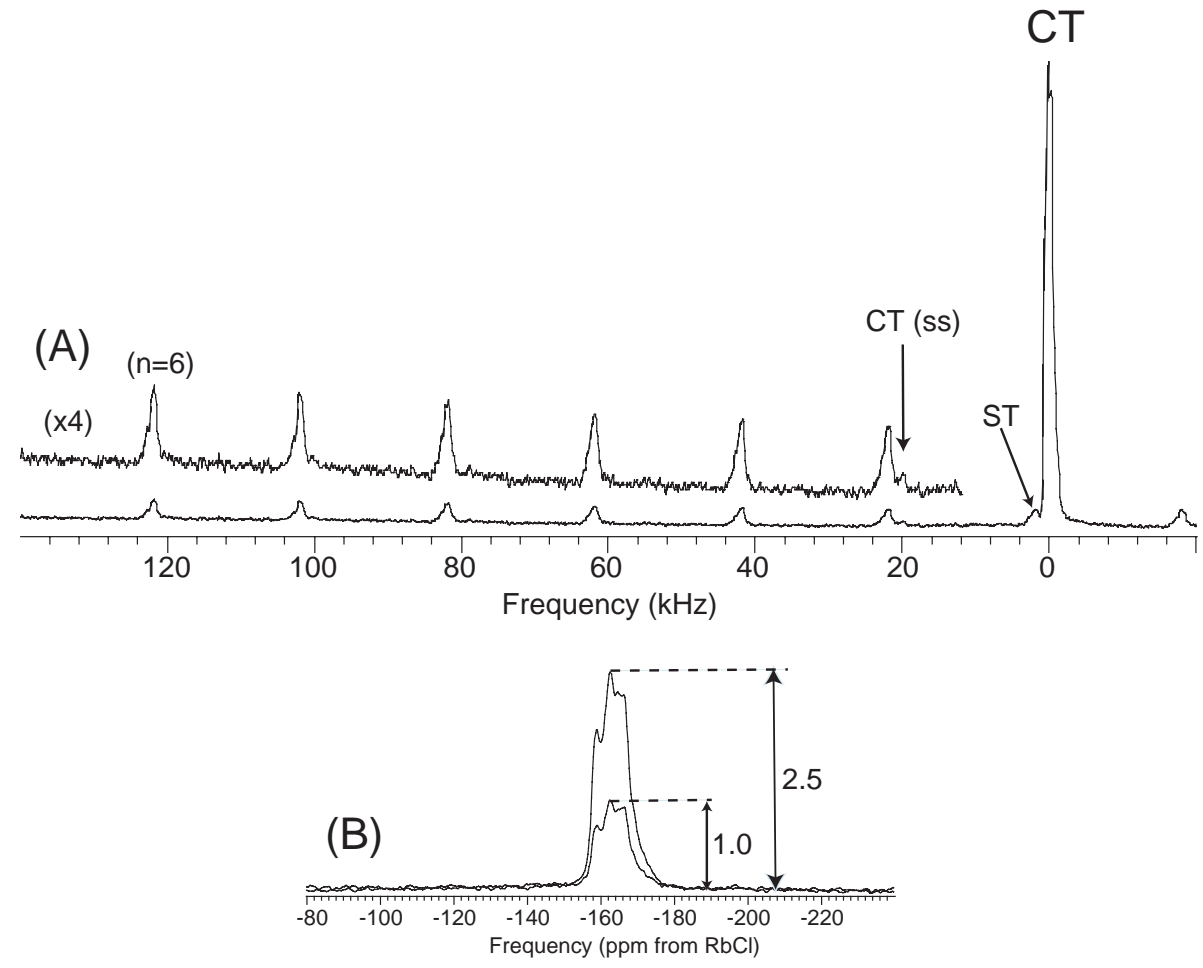

Fig. 2. (A) ${ }^{87} \mathrm{Rb}$ spectrum of $\mathrm{RbNO}_{3}$ (10 k scans) acquired at a spinning rate of $20 \mathrm{kHz}$ showing CT and ST signals. Only one side of the spinning sideband envelope is shown. (B) Comparison of CT intensity obtained from WURST [12,13] adiabatic inversion pulse $(\tau=5 \mathrm{~ms}$, excitation width $=3 \mathrm{kHz}, \nu_{r f}=5.5 \mathrm{kHz}$ ) with no enhancement. All experiments were performed on a Bruker DMX 400 spectrometer using a Bruker $2.5 \mathrm{~mm}$ MAS probehead. The magic-angle was set using $\mathrm{K}^{79} \mathrm{Br}$, and further calibrated by maximizing the ST-CT echo intensity in ${ }^{87} \mathrm{RbNO}_{3}$ [14]. Solid RbCl was used to calibrate the rf-field strengths and used as chemical shift reference. The equilibrium magnetization recovery delay used was approximately $500 \mathrm{~ms}$. Typically, the WURST excitation widths used were slightly larger than the anisotropic linewidth of the satellite spinning sidebands. For creating a WURST pulse, the Bruker ShapeTool ${ }^{\circledR}$ was used.

and using a dwell time of half a rotor period in order to separate the even and odd spinning sidebands. The odd sidebands contain little to no contribution from the central transition. For spin $I=3 / 2$ one can see that the second-order anisotropic broadening of the satellites are slightly narrower than the central transition. For spin $I=5 / 2$ the inner satellite pair is significantly narrower, whereas for spins $I=7 / 2$ and $9 / 2$ it is the 2nd inner satellite pair, $\langle \pm 5 / 2, \pm 3 / 2\rangle$ that is narrowest. This well-known narrowing [17$22]$, can be readily exploited with adiabatic inversion pulses to perform spectral editing of the central transition region. Thus, our approach is to use a $(\pi / 2)_{\mathrm{CT}^{-}}-(\pi)_{\mathrm{ST}_{1}}-$ $(\pi / 2)_{\mathrm{CT}}$ sequence, where the central transition of all sites are pre-saturated by a $(\pi / 2)_{\mathrm{CT}}$ pulse, followed by restoration of the desired site's central transition polarization by selective inversion of its innermost satellite transition prior to detection with a central transition selective $\pi / 2$ pulse. An additional advantage of this approach over $(\pi / 2)_{\mathrm{CT}}-\mathrm{RAPT}-(\pi / 2)_{\mathrm{CT}}$ is that the edited spectrum is enhanced compared to both the conventional Bloch decay experiment and the edited $(\pi / 2)_{\mathrm{CT}}-\mathrm{RAPT}-(\pi / 2)_{\mathrm{CT}}$ experiment $[3,4,6,8]$ due to the use of selective inversion rather than selective saturation. 
Odd Sidebands

(Satellite Transitions Only)
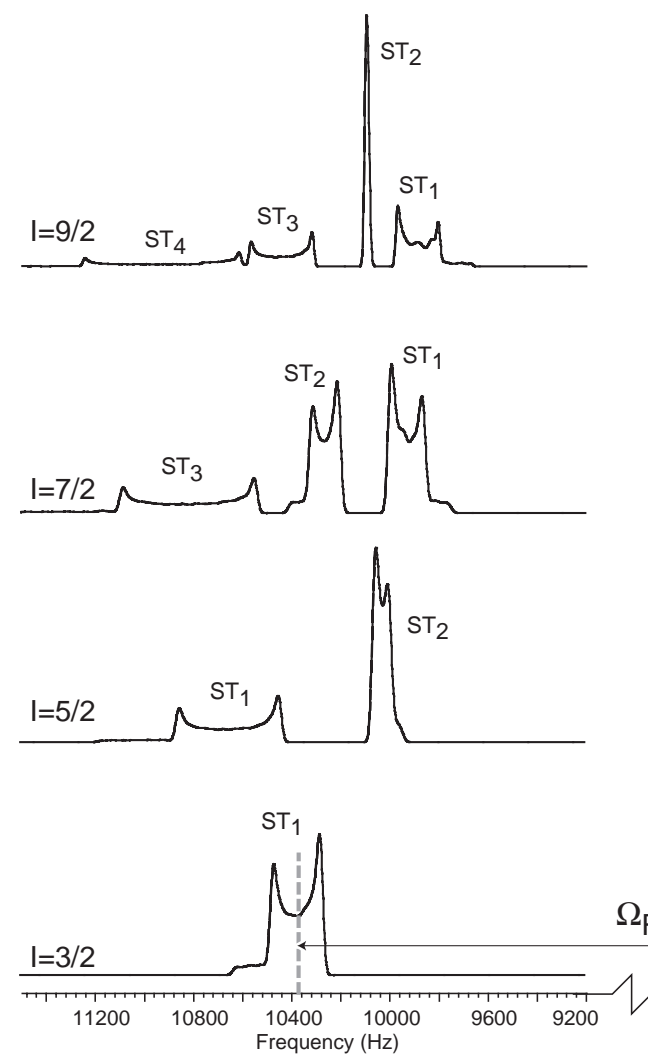

Centerband and Even Sidebands (Satellite and Central Transitions)

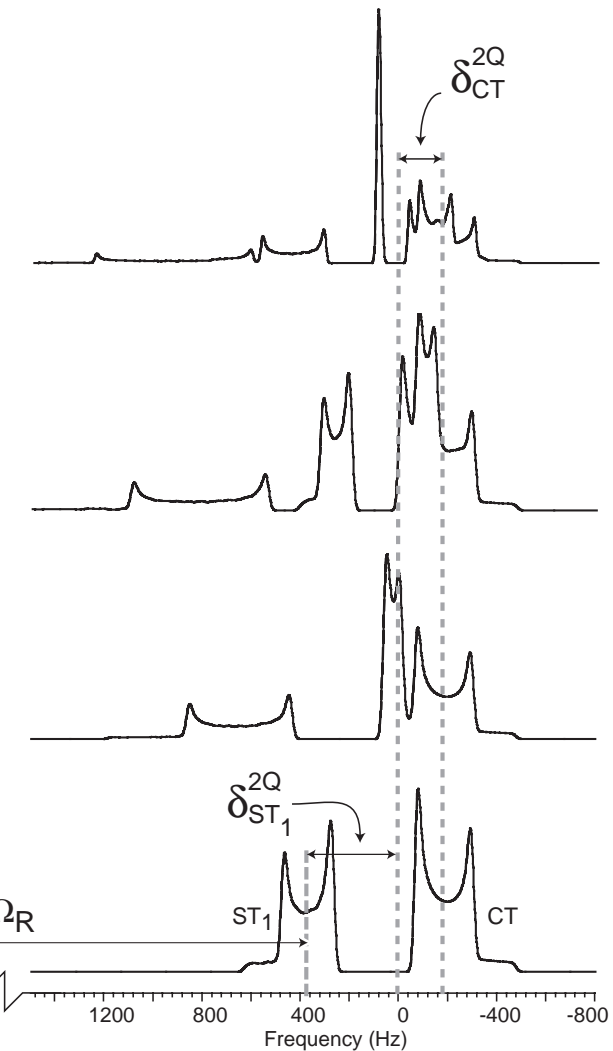

Fig. 3. Simulated central and satellite transitions spectra for spin $I=3 / 2,5 / 2,7 / 2$, and $9 / 2$ nuclei with $C_{q}$ values of $1.0,2.04,3.13$, and $4.24 \mathrm{MHz}$, respectively using half-rotor synchronized acquisitions to separate even and odd sidebands. The $C_{q}$ value for each spin $I$ was adjusted for constant central transition line widths $\left(\eta_{q}=0.0\right.$ and $\left.\nu_{L}=131.45 \mathrm{MHz}\right)$. The second-order shifts[17] of the central $\left(\delta_{C T}^{2 Q}\right)$ and satellite transitions $\left(\delta_{S T}^{2 Q}\right)$ are given by $\delta_{m, m-1}^{2 Q}=\frac{-3[I(I+1)-9 m(m-1)-3]}{40 \nu_{L}^{2} I^{2}(2 I-1)^{2}} C_{q}^{2}\left(1+\frac{\eta_{q}^{2}}{3}\right) \times 10^{6}(\mathrm{ppm})$. For spin $7 / 2$ and $9 / 2$ nuclei, the central and the inner satellite transitions $\left(\mathrm{ST}_{1}\right)$ overlap.

As an example we use the ${ }^{87} \mathrm{Rb}$ spectrum of a mixture of $\mathrm{Rb}_{2} \mathrm{SO}_{4}$ and $\mathrm{RbClO}_{4}$, shown in Fig. 4. $\mathrm{Rb}_{2} \mathrm{SO}_{4}$ contains two $\mathrm{Rb}$ sites, while $\mathrm{RbClO}_{4}$ contains one (see Table 1). In the mixture spectrum, the $\mathrm{CT}$ resonance of $\mathrm{Rb}_{2} \mathrm{SO}_{4}$-II overlaps with the $\mathrm{CT}$ resonance of the $\mathrm{RbClO}_{4}$ site. In contrast, the $\mathrm{ST}$ resonances of all three sites are better resolved, although there still is partial overlap of the $\mathrm{Rb}_{2} \mathrm{SO}_{4}$-I and $\mathrm{Rb}_{2} \mathrm{SO}_{4}$-II ST resonances. Using the $(\pi / 2)_{\mathrm{CT}^{-}}-(\pi)_{\mathrm{ST}_{1}}-(\pi / 2)_{\mathrm{CT}}$ sequence we obtained the edited spectra shown in Fig. 4C, D, and $\mathrm{E}$ for each site,

\begin{tabular}{c|cc|cc}
\hline \hline Site & $\begin{array}{c}C_{q} \\
(\mathrm{MHz})\end{array}$ & $\begin{array}{c}\eta_{q} \\
-\end{array}$ & $\begin{array}{c}\delta_{C T}^{2 Q \dagger} \\
\mathrm{Hz}\end{array}$ & $\begin{array}{c}\delta_{S T}^{2 Q \dagger} \\
\mathrm{Hz}\end{array}$ \\
\hline $\mathrm{Rb}_{2} \mathrm{SO}_{4}-\mathrm{I}$ & 2.67 & 0.89 & -1718 & 3436 \\
\hline $\mathrm{RbClO}_{4}$ & 3.2 & 0.21 & -1979 & 3959 \\
\hline $\mathrm{Rb}_{2} \mathrm{SO}_{4}-\mathrm{II}$ & 5.28 & 0.13 & -5343 & 10686 \\
\hline \hline
\end{tabular}

Table 1

Quadrupolar parameters and relative seondorder quadrupolar shifts of rubidium salts. ${ }^{\dagger}$ Represents second-order shifts for the CT and $\mathrm{ST}$, respectively. 


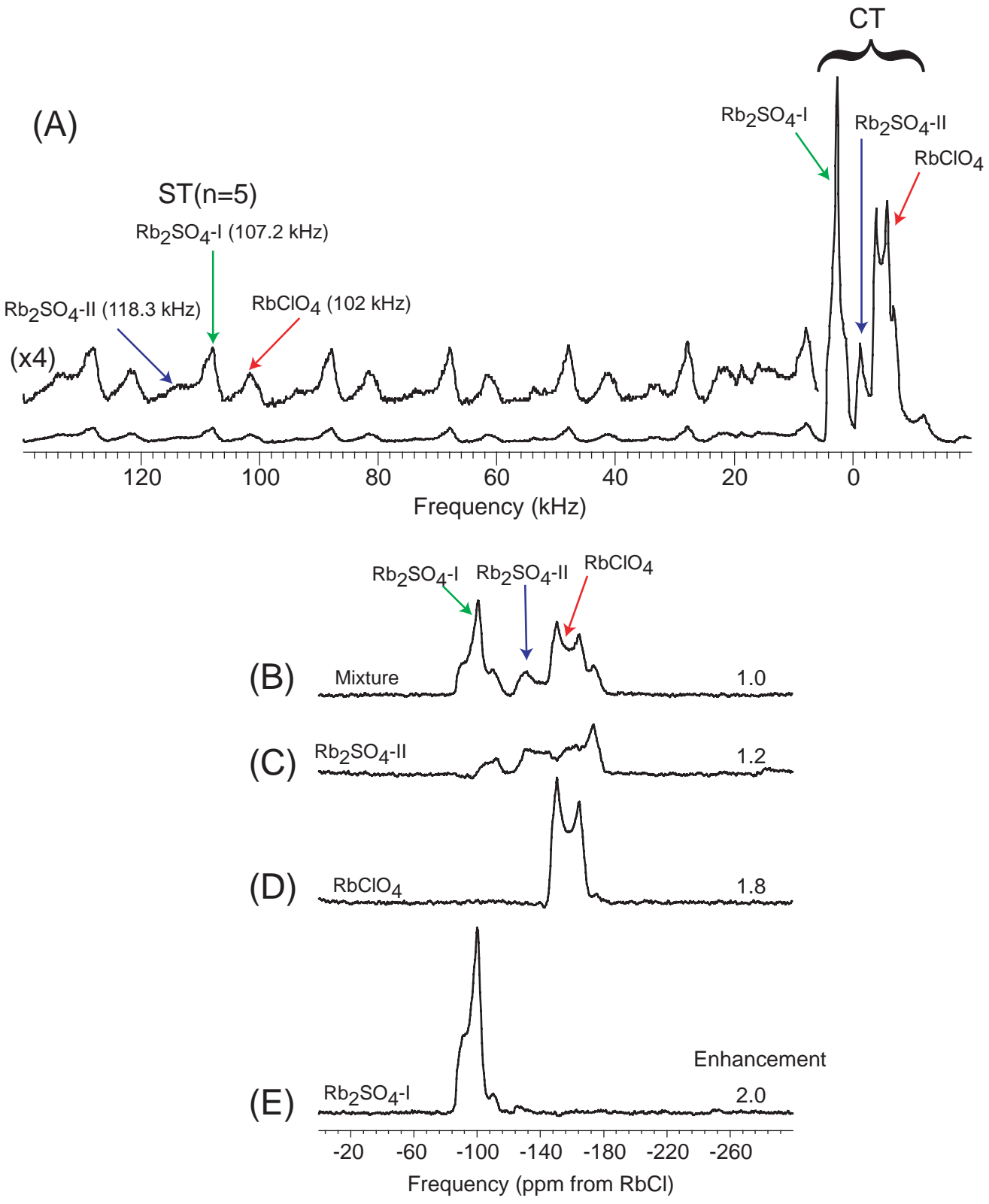

Fig. 4. (A) ${ }^{87} \mathrm{Rb}$ spectrum of a $1: 1$ mixture of polycrystalline $\mathrm{RbClO}_{4}$ and $\mathrm{Rb}_{2} \mathrm{SO}_{4}$ [15,23] (40 $\mathrm{k}$ scans) acquired at a spinning rate of $20 \mathrm{kHz}$ showing $\mathrm{CT}$ and ST signals. Only one side of the spinning sideband envelope is shown. (B) Single pulse spectrum (512 scans) (and (C)-(E) $(\pi / 2)_{\mathrm{CT}^{-}}-(\pi)_{\mathrm{ST}_{1}}-(\pi / 2)_{\mathrm{CT}}$ edited spectra (512 scans) for each site (CT region only). In each case, the inversion pulse was applied on one spinning sideband at the chosen offset as shown in (A). The adiabatic pulse parameters for the different sites are as follows: (C) $\tau=2 \mathrm{~ms}$, excitation width $=$ $8 \mathrm{kHz}, \nu_{r f}=8.5 \mathrm{kHz}$. (D) $\tau=5 \mathrm{~ms}$, excitation width $=3 \mathrm{kHz}, \nu_{r f}=5.5 \mathrm{kHz}$. (E) $\tau=5 \mathrm{~ms}$, excitation width $=3 \mathrm{kHz}, \nu_{r f}=5.5 \mathrm{kHz}$. The spectrometer offset was placed at the middle of the $\mathrm{CT}$ resonances to minimize the off-resonance effects that are caused by the low power read pulse. 
with edited site enhancements of 2.0, 1.8, and 1.2 for $\mathrm{Rb}_{2} \mathrm{SO}_{4}-\mathrm{I}, \mathrm{RbClO}_{4}$ and $\mathrm{Rb}_{2} \mathrm{SO}_{4}{ }^{-}$ II, respectively. The approach works well for two of the three sites, with the inversion being more efficient for smaller $C_{q}$ sites. Some residual $\mathrm{Rb}_{2} \mathrm{SO}_{4}$-I resonance is obtained in the $\mathrm{Rb}_{2} \mathrm{SO}_{4}$-II edited spectrum because slight spectral overlap of ST resonances prevents the inversion pulse from being completely selective on the $\mathrm{Rb}_{2} \mathrm{SO}_{4}{ }^{-}$ II ST resonance. A lower than expected CT enhancement may arise from the $(\pi / 2)_{\mathrm{CT}}$ pulse not being completely CT selective, thus affecting the ST populations to some small degree. The spectral editing based on selective inversion is not limited to spin $3 / 2$ nuclei; significant signal enhancements of the edited sites could be achieved for higher spin systems.

\section{Acknowledgments}

This material is based upon work supported by the National Science Foundation under Grants CHE 0111109. Any opinions, findings and conclusions or recommendations expressed in this material are those of the author(s) and do not necessarily reflect the views of the National Science Foundation. PJG also acknowledges Le Studium, Orléans, France.

\section{References}

[1] Z. Yao, H.-T. Kwak, D. Sakellariou, L. Emsley, P. J. Grandinetti, Sensitivity enhancement of the central transition NMR signal of quadrupolar nuclei under magic-angle spinning, Chem. Phys. Lett. 327 (2000) 85-90.
[2] H.-T. Kwak, S. Prasad, Z. Yao, P. J. Grandinetti, J. R. Sachleben, L. Emlsey, Enhanced sensitivity in RIACT/MQ-MAS NMR experiments using rotor assisted population transfer, J. Magn. Reson. 150 (2001) 71-80.

[3] S. Prasad, H. T. Kwak, T. Clark, P. J. Grandinetti, A simple technique for determining nuclear quadrupole coupling constants using RAPT solid-state NMR spectroscopy, J. Am. Chem. Soc. 124 (18) (2002) 4964-4965.

[4] H.-T. Kwak, S. Prasad, T. M. Clark, P. J. Grandinetti, Selective suppression and excitation of solid-state NMR resonances based on quadrupole coupling constants, J. Magn. Reson. 160 (2003) 107-113.

[5] S. Prasad, T. Clark, T. H. Sefzik, H.-T. Kwak, Z. Gan, P. J. Grandinetti, Solidstate multinuclear magnetic resonance investigation of pyrex ${ }^{\circledR}$, J. Non-Cryst. Solids 352 (26-27) (2006) 2834-40.

[6] L. J. Smith, C. Seith, Site-selective QPASS for the isolation of large quadrupolar coupling environments, J. Magn. Reson. 179 (2006) 164-168.

[7] D. Massiot, V. Montouillout, F. Fayon, P. Florian, C. Bessada, Order-resolved sideband

separation in magic angle spinning NMR of half integer quadrupolar nuclei, Chem. Phys. Lett. 272 (1997) 295-300.

[8] M. Eden, Quadrupolar coupling selective cross-polarization in solid state NMR, Phys. Chem. Chem. Phys. 8 (17) (2006) 1994-99.

[9] R. Siegel, T. T. Nakashima, R. E. Wasylishen, Signal enhancement of NMR spectra of half-integer quadrupolar nuclei in solids using hyperbolic secant pulses, Chem. Phys. Lett. 388 (2004) 441-445.

[10] M. S. Silver, R. I. Joseph, D. I. Hoult, Selective spin inversion in nuclear magnetic 
resonance and coherent optics through an exact solution of the bloch-riccati equation, Phys. Rev. A 31 (4) (1985) 2753-2755.

[11] S. Vega, Y. Naor, Triple quantum NMR on spin systems with $I=3 / 2$ in solids, J. Chem. Phys. 75 (1981) 75-86.

[12] E. Kupce, R. Freeman, Adiabatic pulses for wideband inversion and broadband decoupling, J. Magn. Reson. A 115 (1995) 273-276.

[13] E. Kupce, R. Freeman, Optimized adiabatic pulses for wideband spin inversion, J. Magn. Reson. A. 118 (1996) 299-303.

[14] S. E. Ashbrook, S. Wimperis, Satellitetransition MAS NMR of $\operatorname{spin} \mathrm{I}=3 / 2,5 / 2$, $7 / 2$, and 9/2 nuclei: Sensitivity, resolution, and practical implementation, J. Magn. Reson. 156 (2) (2002) 269-282.

[15] J. H. Baltisberger, S. L. Gann, E. W. Wooten, T. H. Chang, K. T. Mueller, A. Pines, ${ }^{87} \mathrm{Rb}$ dynamic-angle spinning NMR spectroscopy of inorganic rubidium salts, J. Am. Chem. Soc. 114 (1992) 748993.

[16] R. Siegel, T. T. Nakashima, R. E. Wasylishen, Sensitivity enhancement of solid-state NMR spectra of half-integer spin quadrupolar nuclei using hyperbolic secant pulses: Applications to spin-5/2 nuclei, Chem. Phys. Lett. 421 (4-6) (2006) 529-533.

[17] A. Samoson, Satellite transition highresolution NMR of quadrupolar nuclei in powders, Chem. Phys. Lett. 119 (1985) 2932 .

[18] C. Jäger, How to get more from ${ }^{27} \mathrm{Al}$ MAS NMR by high-speed satellite-transition spectroscopy, J. Magn. Reson. 92 (1992) 353-362.

[19] D. Massiot, D. Müller, T. Hübert, M. Schneider, A. P. M. Kentgens, B. Coté,
J. P. Coutures, W. Gessner, DOR and MAS NMR study of ${ }^{27} \mathrm{Al}$ : Reexamination of the aluminum borate $9 \mathrm{Al}_{2} \mathrm{O}_{3}-2 \mathrm{~B}_{2} \mathrm{O}_{3}$, Solid State NMR 5 (1995) 175-180.

[20] S. E. Ashbrook, S. Wimperis, Rotorsynchronized acquisition of quadrupolar satellite-transition NMR spectra: practical aspects and double-quantum filtration, J. Magn. Reson. 177 (1) (2005) 44-55.

[21] J.-P. Amoureux, J. Trebosc, Resolution enhancement in 1D solid-state NMR spectra of spin-9/2 quadrupolar nuclei, J. Magn. Reson. 181 (2006) 311-317.

[22] D. Massiot, J. Hiet, N. Pellerin, F. Fayon, M. Deschamps, S. Steuernagel, P. J. Grandinetti, Two-dimensional one pulse MAS of half-integer quadrupolar nuclei, J. Magn. Reson. 181 (2006) 310-315.

[23] T. Vosegaard, J. Skibsted, H. Bildsoe, H. J. Jakobsen, Quadrupole coupling and anisotropic shielding from singlecrystal NMR of the central transition for quadrupolar nuclei. ${ }^{87} \mathrm{Rb} \mathrm{NMR}$ of $\mathrm{RbClO}_{4}$ and $\mathrm{Rb}_{2} \mathrm{SO}_{4}$, J. Magn. Reson. 122 (1996) 111-119. 